Article

\title{
The Role of Journalism on YouTube: Audience Engagement with 'Superbug' Reporting
}

\author{
Monika Djerf-Pierre ${ }^{1,2, *}$, Mia Lindgren ${ }^{2}$ and Mikayla Alexis Budinski ${ }^{2}$ \\ ${ }^{1}$ Department of Journalism, Media and Communication, University of Gothenburg, 40530 Gothenburg, Sweden; \\ E-Mail: monika.djerf-pierre@jmg.gu.se \\ ${ }^{2}$ School of Media, Film and Journalism, Monash University, Melbourne, VIC 3145, Australia; \\ E-Mails: mia.lindgren@monash.edu (M.L.), mikayla.budinski@monash.edu (M.A.B.) \\ * Corresponding author
}

Submitted: 29 September 2018 | Accepted: 3 January 2019 | Published: 21 March 2019

\begin{abstract}
Journalism has gradually become 'normalized into social media', and most journalists use social media platforms to publish their work (Bruns, 2018). YouTube is an influential social media platform, reaching over a billion users worldwide. Its extensive reach attracts professional and amateur video producers who turn to YouTube to inform, entertain and engage global publics. Focusing on YouTube, this study explores the place for journalism within this media ecology. This study uses a mixed-method approach to examine forms of audience engagement to YouTube videos about antimicrobial resistance (AMR), or so called "superbugs", caused by overuse and misuse of antibiotics. The analysis focuses on the most viewed YouTube videos about AMR between 2016 and 2018, and compares engagement themes expressed in comments to journalistic videos with popular science videos. The most viewed videos about AMR on YouTube are professionally produced educational popular science videos. The qualitative analysis of 3,049 comments identifies seven main forms of high-level engagement, including expressions of emotions, blame and calls for action. This study shows that journalism plays an important role on YouTube by generating audience discussions about social and political accountability. Our findings demonstrate that journalism videos were associated with propositions for political, economic and social/lifestyle actions, while popular science videos were associated with medicines, scientific or pseudo-scientific, and medical practice changes.
\end{abstract}

\section{Keywords}

antibiotic resistance; antimicrobial resistance; audience engagement; popular science; social media; superbugs; user comments; video journalism; YouTube

\section{Issue}

This article is part of the issue "Journalism and Social Media: Redistribution of Power?", edited by Marcel Broersma and Scott Eldridge II (University of Groningen, The Netherlands).

(C) 2019 by the authors; licensee Cogitatio (Lisbon, Portugal). This article is licensed under a Creative Commons Attribution 4.0 International License (CC BY).

\section{Introduction-The Place for Journalism in the Current Media Ecology}

Journalism has gradually become normalized into social media, and journalists and media companies actively publish and promote their material on social media platforms (Bruns, 2018). Journalists are active on both Facebook and Twitter, and their journalistic content, such as news and current affairs programs, is also frequently published on YouTube. The aim of this study is to explore the place for journalism within this media ecology. The focus is on journalism on YouTube, examining how journalistic content engages audiences around important societal issues by comparing journalism videos with popular science videos on YouTube.

Audience engagement, demonstrated via shares, likes and comments online, has become a buzzword in the media industry. The economic strain coupled with an uncertain digital media landscape has turned media's focus on audience behaviour and preferences to inform 
business models for online news (Cherubini \& Nielsen, 2016; Ksiazek, Peer, \& Zivic, 2015; Mersey, Malthouse, \& Calder, 2010; Peters \& Broersma, 2017; Powers, 2015). Editors track figures on a story-by-story basis to try to determine what particular elements of journalistic practices, including story selection, content design, writing style and timing of the publication generate greater or less engagement in terms of views.

The blind chase to maximize low-level engagement such as 'views' fuelled by business imperatives may not only result in journalists and editors neglecting the normative functions or institutional values of journalism, but be at its expense (Couldry, 2015; Steel, 2017). These classic and enduring functions and values of journalism as an institution include its role as disseminator of information of common interest, acting as a watchdog against the powerful, and stimulating and hosting public deliberation on matters of importance (Braun \& Gillespie, 2011; Couldry, 2017; Meyer \& Carey, 2014; Peters \& Broersma, 2017; Tenenboim \& Cohen, 2015; Wolfgang, 2018).

Indeed, further to comments used to inform business models in the media industry, online comments platforms have the potential to serve as spaces where audiences/users express attitudes not only towards the specifics of the journalistic content in question, but broader social and political issues, thereby constituting a public sphere which facilitates the expression of opinion and deliberation of important issues (Ben-David \& Soffer, 2018; Ksiazek, Peer \& Zivic, 2015; McDermott, 2018; Santana, 2015).

However, the quantity of comments does not convey the nature and quality of audience engagement in the public sphere. Instead of being civil and respectful (Ksiazek et al., 2015; Rowe, 2015; Santana, 2015), online debates are often uncivil, and sometimes even overtly racists (Richardson \& Stanyer, 2011; Santana, 2015). Measures of low-level engagement such as 'views' also fail to capture how deeply stories affect audiences and the impact the story may have had on their subsequent behavior (Stroud, Steiner, Alibhai, Lang, \& Purcell, 2017). Peters and Broersma (2017) thus argue for a 'bottomup', audience-centric investigation of engagement. This means examining how the audience actually engages with journalistic content independent of any preconceived notions of journalism's normative functions.

This study examines how audiences use comments to express engagement to YouTube videos focused on so called "superbugs", or antimicrobial resistance (AMR). $A M R$ is one of the greatest global challenges in the 21st century, caused by the overuse and misuse of antibiotics in human medicine and food production (World Health Organization, 2015). YouTube is an influential social media platform, and its extensive reach attracts public health communicators to turn to YouTube to educate and influence global publics. Indeed, the most viewed videos about AMR on YouTube are popular science videos with clear educational purposes, explaining the biological processes involved in the evolution of resis- tant bacteria. In contrast, journalism videos about AMR on YouTube mainly consist of investigative reports clearly engaging with the societal causes and consequences of AMR (Lindgren \& Djerf-Pierre, 2017).

The present study aims to place itself apart from both the fixed normative approaches to engagement and the market-driven approaches directed by news outlets' business imperatives. Using the AMR issue as a case study, we present an audience-centric, bottom-up study of user comments to YouTube videos focused on the following research questions:

- How do audiences express engagement in user comments to YouTube videos about AMR?

- Do the expressions of engagement differ between journalism videos and popular science videos?

We examine the various expressions of engagement that emerge in the comments to videos about AMR resistance. Drawing on differences found in audience's responses to journalism and the popular science videos, we discuss the specific role journalism occupies on YouTube.

We begin the study with an overview of the variety of definitions used by scholars for the concept of engagement within relevant literature. This is followed by a section outlining the mixed-methods approach generating results which point to the differences between audience engagement with journalistic content and other genres on YouTube. The result section describes and compares the engagement themes to the journalism videos with the popular science videos. The article closes with a concluding discussion.

\section{Engaging Audiences with Journalism}

Despite the term 'engagement' being commonly used in countless studies in journalism research, few attempts to define it concretely. Those that do, define it in numerous ways without universal consensus (Chan-Olmsted \& Wolter, 2018; Nelson, 2018). Nelson (2018) characterizes the concept as 'fraught' (p. 531) and confusing across the news industry, despite its status as a 'media industry buzzword' (Lawrence, Radcliffe, \& Schmidt, 2018 , p. 1220). Many concepts are related and are sometimes used interchangeably, such as participation and interactivity. Some definitions focus on mental states and emotional involvement among individual media users (Chan-Olmsted \& Wolter, 2018; Oliphant, 2013), others encompass broader notions of collective and individual experiences with media (Hill \& Steemers, 2017; Mersey et al., 2010). Swart, Peters and Broersma (2017, p. 186) define engagement as the 'specific ways and means by which people connect [to public life] through news.' The broadest possible definition of audience engagement would be to include all audience responses to media 'beyond the level of attention' (Couldry, Livingstone, \& Markham, 2010). However, in the context of "online en- 
gagement", which is the focus of this study, one key theme of interaction appears in many definitions. Further unpacked, online engagement as "interactivity" has two main attributes of interaction: first, that between the user and producer, and second, interaction between users (Boczkowski \& Mitchelstein, 2012; Ksiazek, Peer, \& Lessard, 2016). Our study encompasses both aspects of interactivity however it is not possible to determine exactly who the viewer is engaging with as we do not examine comment threads. The comments can be directed at the producers, other viewers of the videos or anyone in the vast YouTube audience.

Kim, Hou, Han and Himelboim (2016) argue that different levels of cognitive engagement is what separates less from more engagement online. Engagement is conceptualised as a spectrum with lower, or less active engagement at one end, such as viewing or 'liking' content, and higher level and more active engagement such as commenting on content or other comments occurring at the other, with medium level engagement such as 'sharing' falling at various places in-between. When audiences interact with a medium by commenting in a public forum online it is therefore considered to represent a high-level form of engagement. Still, the specific expressions (quality and content) of engagement that are expressed in each comment may vary quite significantly.

In response to the lack of a unitary definition, we opted for a very broad perspective when looking for expressions of audience engagement online. This includes both measures of low-level engagements such as views and likes and a close examination of high-level forms of engagement demonstrated by comments expressing how audiences feel, think and act in response to having viewed a video about AMR on YouTube.

\section{Journalism on YouTube}

This study of the role of journalism is located on one of the most wide-reaching social media platforms, YouTube, an influential and transnational video-sharing platform. YouTube is the second largest search engine in the world, with over 80 percent of users located outside the US. Every day, one billion hours of YouTube video content is watched (Aslam, 2018). It has been described by various sources as a platform, an archive, a library, a medium, a laboratory, a modern-day bard, a storyteller for the digital age, and a source of modern-day mythology (Kavoori, 2015). Burgess and Green describe YouTube as an 'almost incomprehensibly large and highly diverse archive of video content' (2018, p. 14). They define YouTube as mainstream media which has helped redefine what "professional media" looks like-a platform for amateur and professional production and distribution which is experienced in diverse ways by 'different users' (p. 22).

As a global platform for journalism, YouTube offers a plethora of content and news channels (Sumiala \& Tikka, 2013). In addition to providing diverse news content, it suggests videos for viewers to watch based on subject topic relating to previously watched materials. YouTube also plays a role in mediating video content through its algorithm ranking of top results. As Rieder, MatamorosFernandez and Coromina (2018) demonstrate in their study of visibility of YouTube search results, YouTube's search function is designed to highlight what the authors call "'newsy' moments" (p. 63), thereby changing search results from day to day. They also point to how recommendations and subscriptions influence search ranking, with the platform privileging 'channel subscriptions as a means for content creators to build and address an audience' (p. 63).

Briones, Nan, Madden and Waks (2012) study of HPV vaccine coverage on YouTube, shows how the YouTube discourse on controversial subjects can shift relatively quickly, demonstrated by an increasingly negative tone in both user generated videos and viewer responses. However, while YouTube is often conceived of as a place for non-professional producers, that is, amateurs or "ordinary users", to create and upload their own content, Burgess and Green's (2009) study of the most popular videos on YouTube revealed that a large amount of content originates from corporate users ("big media" companies in film, music or television, or web-TV companies). Welbourne and Grant's (2015) study of the characteristics of the most viewed videos about science on YouTube also concludes that professionally generated content is superior in number.

In many cases, the journalistic material published on YouTube is repurposed from traditional media news sites. Television news and current affairs production follows conventions with long-standing expectation of high production values and aesthetics. Peer and Ksiazek's (2011) content analysis of 882 journalistic news videos on YouTube showed that approximately half of the examined videos were repurposed from traditional news media sites. It also showed that the news videos produced specifically for YouTube adhered to traditional journalistic production practices (picture and sound quality, editing techniques, etc.) but diverted from 'common content standards' (p. 45), for example how they used sources and/or in their approach to fairness. In short, their study demonstrated that repurposed news videos from other mediums (such as television news and current affairs programs) adhered to traditional and institutionalised journalism standards in both production approach and content elements. As such, those videos can be considered in a similar way to video journalism published on traditional news channels.

\section{Making Sense of AMR: Comparing Journalism with Other YouTube Genres}

The five journalistic videos analysed for this study are all long-form current affairs productions, repurposed from online or broadcast news organisations, including VICE, The Guardian PBS Frontline (US), and ABC (Australia). To identify what these bring to the table in terms 
of audience responses and engagement, we contrast it with another YouTube genre. As a platform for content, YouTube facilitates comparative studies of different types of videos genres, production approaches and content. YouTube hosts videos from different types of producers with different communicative purposes. In a previous study (Lindgren \& Djerf-Pierre, 2017) examining the most viewed videos about AMR on YouTube, we identified two distinctly different ways of communicating and making sense of AMR on YouTube: investigative long-form journalism and popular science videos providing educational content focused on science and health. Since they afford two distinctly different ways of making sense of the AMR issue, we decided to compare the audience responses to journalism videos with the popular science category.

The journalistic videos emphasize the human and societal impact of AMR, and uncover the social causes and consequences of the spread of resistant bacteria. The journalistic investigations involve on-location reporting with in-depth probing of specific cases; a prevalent use of personal stories of individuals infected by resistant bacteria or plagued by industrial pollution to promote empathy and identification; and accountability interviews, that is, were politicians or industry representatives are held to account.

The popular science videos, on the other hand, generally focus on promoting expert health knowledge, heralding warnings about the general overuse and misuse of antibiotics, and explaining the biological processes that causes bacteria to become resistant to antibiotics, often in great and graphic detail. To make the science concrete and more entertaining to a lay audience the producers draw on familiar storytelling formulas from video games, cartoons, and superhero and monster movies, including an abundant use of cartoons and animations, featuring 'evil' anthropomorphized bacteria fighting antibiotic pills portrayed with human appearances, intentions and behaviours. Although the social causes and consequences, such as the problem with factory farming and pharmaceutical waste are discussed they are rarely the focus of the videos. The five popular science videos in our sample are typical examples of this approach and they are produced by a mix of professional companies such as TED (Ed and Talks) and independent subscription-based producers (GROSS Science, Kurzgesagt, SciShow).

\section{Methodology}

A mixed methods research approach was employed, following Burke, Johnson and Onwuegbuzie's (2004) definition. While the analysis is primarily qualitative, a quantification of engagement was included to supplement the qualitative analysis. Additionally, guided by the audience-centric 'bottom-up' approach to examining engagement advocated by Peters and Broersma (2017), we adopted an inductive rather than deductive approach to the qualitative analysis.
The sample consisted of the five most viewed journalism and five most viewed popular science videos covering the subject of AMR published on YouTube between 2016 and 2018 (Table 1). The videos were found by searching for the videos with most views, using the keywords "antibiotic resistance", "antimicrobial resistance", and "superbugs".

All user comments to the ten videos were downloaded and saved. Sorted by date, the 200 most recent and 200 oldest comments, excluding replies to other comments, posted on each of these videos formed the data set for examination. If the total number of comments were less than 400 then all original comments were included in the data set. This resulted in a total of $n=3,049$ comments which qualified for analysis.

An initial inductive analysis identified seven major reoccurring themes of engagement which assisted in organizing the analysis: (1) Expressing sentiment to video production, (2) Sharing emotions, (3) Sharing personal experiences with AMR, (4) Sharing AMR information and ideas, (5) Assigning blame, (6) Proposing action, and (7) Other (linguistic and rhetorical expressions). All themes included further levels of analysis. For example, within the theme of proposing action, commenters engaged by expressing particular ideas for courses of action, which we defined as "sub-themes".

Engagement themes were operationalized by defining the unit of analysis as the textual expression made by users via comments which conveyed a specific thought or idea. The unit of analysis could range from a single word to the comment as a whole. Furthermore, engagement themes were not mutually exclusive in that a single unit of analysis could be coded as two or more themes simultaneously.

The dataset of qualifying comments was imported into NVivo for systematic coding in two phases following a codebook developed by the researchers. New themes generated by further inductive analyses were added to the codebook. In the second phase of analysis, the entire data set was once again systemically coded and clustered according to the parameters of the final updated codebook.

The compilation of comments sorted by themes and sub-themes of engagement provided the data for the qualitative analysis of engagement. To supplement the qualitative analysis, a quantification of the qualitative data was also provided by calculating the frequency of themes and sub-themes which occurred across all comments, comments in each category of video (journalism vs popular science) and comments per specific video in each category.

\section{Results: Expressions of Engagement in YouTube Comments}

We start by looking at low-level indicators of engagement, such as views and likes (Table 2). This part of the analysis only allows us to assess the popularity of 
Table 1. Sample of videos.

\begin{tabular}{|c|c|c|c|c|}
\hline VIDEO & $\begin{array}{l}\text { Views March } \\
2016\end{array}$ & $\begin{array}{l}\text { Views Feb } \\
2018\end{array}$ & $\begin{array}{l}\text { Producer/ } \\
\text { Publisher }\end{array}$ & Category \\
\hline \multicolumn{5}{|l|}{ POPULAR SCIENCE } \\
\hline The Antibiotic Apocalypse Explained & $772 \mathrm{~K}$ & $3.7 \mathrm{M}$ & Kurzgesagt & Popular science (animation) \\
\hline Attack of the Superbugs & $476 K$ & $593 K$ & SciShow & Popular science (science show) \\
\hline $\begin{array}{l}\text { What Causes Antibiotic Resistance? } \\
\text { - Kevin Wu }\end{array}$ & $425 K$ & $1.3 \mathrm{M}$ & TED-Ed & Popular science (animation) \\
\hline Rise of the Superbugs & $196 K$ & $418 \mathrm{~K}$ & $\begin{array}{l}\text { It's Okay to Be } \\
\text { Smart, GROSS } \\
\text { Science }\end{array}$ & Popular science (science show) \\
\hline $\begin{array}{l}\text { Maryn McKenna: What Do We Do } \\
\text { When Antibiotics Don't Work } \\
\text { Any More? }\end{array}$ & $80 K$ & $139 K$ & TED Talks & Popular science (live lecture) \\
\hline \multicolumn{5}{|l|}{ JOURNALISM } \\
\hline $\begin{array}{l}\text { The Virus That Kills Drug-Resistant } \\
\text { Superbugs }\end{array}$ & - & $653 \mathrm{~K}$ & $\begin{array}{l}\text { Motherboard } \\
\text { (related to VICE) }\end{array}$ & Documentary \\
\hline $\begin{array}{l}\text { Pig MRSA Superbug Spreading to } \\
\text { Humans through Pork }\end{array}$ & $443 K$ & $\begin{array}{l}\text { NA } \\
\text { (republished } \\
\text { with new } \\
\text { title) }\end{array}$ & $\begin{array}{l}\text { Journeyman } \\
\text { Pictures, } \\
\text { Guardian }\end{array}$ & $\begin{array}{l}\text { Documentary, investigative } \\
\text { journalism }\end{array}$ \\
\hline $\begin{array}{l}\text { Superbugs: The Dark Side of India's } \\
\text { Drug Boom }\end{array}$ & $174 K$ & $344 K$ & VICE News & $\begin{array}{l}\text { Documentary, investigative } \\
\text { journalism }\end{array}$ \\
\hline $\begin{array}{l}\text { The Rise of The Superbugs } \\
\text { Resistant to Antibiotics }\end{array}$ & $70 \mathrm{~K}$ & $42 \mathrm{~K}$ & $\begin{array}{l}\text { Journeyman } \\
\text { Pictures, } A B C\end{array}$ & $\begin{array}{l}\text { Documentary, investigative } \\
\text { journalism }\end{array}$ \\
\hline $\begin{array}{l}\text { Hunting the Nightmare Bacteria } \\
\text {-PBS Frontline }\end{array}$ & - & $145 K$ & $\begin{array}{l}\text { Wandering } \\
\text { Planet }\end{array}$ & Documentary \\
\hline
\end{tabular}

Table 2. Comparison of conventional measures of engagement for "Journalism" and "Popular Science" videos about AMR on YouTube.

\begin{tabular}{llll}
\hline & “Journalism" (J) videos & “Popular Science" (S) videos & RATIO (J/S) \\
\hline Average number of views & 359,241 & $1,258,553$ & 0.29 \\
Likes per 1,000 views & 9.99 & 22.09 & 0.45 \\
Dislikes per 1,000 views & 0.29 & 0.25 & 1.17 \\
Comments per 1,000 views & 2.28 & 2.28 & 1.00 \\
\hline
\end{tabular}

Note: Number of views at time of capture. Ratio $(\mathrm{J} / \mathrm{S})$ was calculated by dividing the frequency of engagement themes for 'Journalism' videos by that of 'Popular Science' videos. A Ratio of 1.00 indicates that the frequency of engagement for a particular category was equal for 'Journalism' and 'Popular Science' videos. A ratio above 1.00 indicates that the engagement category was exhibited more frequently in 'Journalism' videos, while a ratio below 1.00 that the engagement category was exhibited more frequently in 'Popular Science' videos.

the two different video genres. While both attracted quite a significant number of views, the popular science videos were viewed approximately three times more than journalism videos and had twice as many likes per 1,000 views. The popular science videos were more "popular"-and scored higher on a low-level engagement scale. However, much of the difference can be explained by one of the popular science videos (The Antibiotic Apocalypse Explained) having 3.75 million views and over 10,000 comments. Further, when we look at the prevalence of comments, a high-level indicator of engagement, it is exactly the same for both categories of videos: 2.28 comments per 1,000 views.

This finding is in line with the points made in the introduction of this article about the limitation of using quantitative measures of engagement, supporting the rational for this study to drill deeper into the content and quality of comments to examine the place for journalism reporting about AMR on YouTube. The thematic analysis of engagement below begins with an analysis of the 
journalism videos before comparing them with the popular science videos. A quantitative summary of engagement themes and frequency in the journalism and popular science videos, respectively, is presented as overview in Table 3.

\subsection{Expressing Sentiments about the Video Production}

The first engagement theme dealt with audience sentiment to the production and framing of the video. This theme addressed the viewers' evaluations of the video and its elements, rather than viewers' sentiments or attitudes to science, government, society or people in general. Three types of overall sentiment were identified: positive, negative, and neutral.

In positive sentiments, audience members commended the journalists for quality reporting (example 1). They also commented positively on the reporters' performances and appearances.

(1) 'We have been losing this battle and there has not really been much coverage. Thanks Journeyman for shining some light on this unheard of epidemic. If this was covered like Ebola the people would know the risks and dangers.' (Pig MRSA)

Equally, the journalism videos attracted negative comments criticising both the video and the journalists on a range of issues, including accusations of sensationalism (2), bias, presentations of inaccurate or misleading facts, reporter incompetency, and a lack of journalistic social responsibility.

(2) 'I didn't make it through more than the first few minutes of this video-it was mostly sensationalized, with gross oversimplifications of the science (and they got the science of Gram-negative bacteria all wrong)' (Hunting the Nightmare Bacteria)

However, most comments did not display a clear negative or positive attitude to the videos. Instead, viewers remarked on a specific element or section of the video without being explicitly critical or laudatory. Key examples are comments including a time code pointing to an exact part of the video ('32:22'), in order to either draw attention to something the commenter found particularly noteworthy (3) or to highlight the section of the video that triggered a personal association or reflection (4).

(3) 'on a lighter note...is it me or is this guy trying too hard to look shocked and interested at the same time 32:22 lol' (Hunting the Nightmare Bacteria)

(4) 'The lady at 7:33 sounds like Dexter' (The Virus that Kills Drug-Resistant Superbugs)

In the latter case, viewers commonly made references to various popular culture phenomena such as film, videogames, TV-series etc. Almost four out of 100 comments to the journalism videos referenced popular culture (4-5). Another noticeable and frequent feature of audience engagement with the YouTube videos were displays of humour, where comments included sarcastic remarks or linguistic expressions indicating that viewers found the content amusing or funny (e.g. writing "LOL").

(5) 'I thought this was about some new Ubisoft videogame.' (The Rise of Superbugs Resistant to Antibiotics)

A comparison of the journalism and popular science videos showed that for both categories, positive sentiments were more often expressed than negative. Secondly, neutral comments were more frequently expressed than both positive and negative comments combined. Overall, popular science videos had more positive comments, and comments that expressed humour and referenced popular culture.

\subsection{Sharing Emotions}

The second engagement theme involved comments from viewers expressing an emotional response to the video content. Two sub-themes, "empathy" (6) and "hope/ optimism" were identified and included under "positive emotions" while "negative emotions" comprised of "anger/resentment" (7), "defeatism/pessimism" and "worry/anxiety" sub-themes.

(6) 'it ALWAYS causes me too well-up to see a grown man cry' (The Dark Side of India's Drug Boom)

(7) 'Big Pharma won't spend money developing medicine that we can only take for 7-14 days! They want long-term meds in use-all about the money! Fucking Greedy Bastards may they all get the superbug and die a slow death.' (Hunting the Nightmare Bacteria)

Emotional responses were relatively common, with 16 of 100 comments to the journalism videos including some kind of emotional display. However, the negative emotions clearly outnumbered the positive. The negative emotions to journalism videos ranged from provoking anger, to pessimism and worry. The anger was mostly directed at the actors and institutions that were the targets of journalistic scrutiny in the respective program, e.g. the pharmaceutical industry ("big pharma" and "capitalism"), or factory farming (but also "meat eater"). In response to the current affairs videos focusing on AMR in India and China, viewers' anger was also directed at the country's government or (with clear xenophobic overtones) the country's culture at large. The display of anger in comments thus closely corresponds to the engagement theme assigning blame and accountability, which we discuss below. 
Table 3. Frequency of themes of engagement per 100 comments for journalism and popular science videos about AMR on YouTube.

\begin{tabular}{|c|c|c|c|}
\hline \multirow[b]{2}{*}{ Engagement themes per 100 comments } & \multicolumn{2}{|c|}{ Engagement theme categories } & \multirow[b]{2}{*}{ RATIO (J/S) } \\
\hline & $\begin{array}{l}\text { "Journalism" (J) } \\
\text { videos }\end{array}$ & $\begin{array}{c}\text { "Popular Science" (S) } \\
\text { videos }\end{array}$ & \\
\hline EXPRESSES SENTIMENT TO VIDEO PRODUCTION & 21.9 & 34.6 & 0.63 \\
\hline Positive sentiment to video & 6.1 & 12.1 & 0.50 \\
\hline Negative sentiment to video & 4.4 & 6.8 & 0.65 \\
\hline Neutral/other remark about video production & 11.4 & 15.7 & 0.73 \\
\hline SHARES EMOTIONS-TOTAL & 16.4 & 13.4 & 1.22 \\
\hline NEGATIVE EMOTIONS-SUB TOTAL & 11.7 & 10.8 & 1.08 \\
\hline Anger/Resentment & 4.6 & 1.2 & 3.83 \\
\hline Pessimism/Defeatism & 3.4 & 3.8 & 0.89 \\
\hline Worry/Anxiety & 3.7 & 5.8 & 0.64 \\
\hline POSITIVE EMOTIONS-SUB TOTAL & 4.6 & 2.7 & 1.70 \\
\hline Empathy & 3.4 & 0.2 & 17.00 \\
\hline Hope/Optimism & 1.2 & 2.5 & 0.48 \\
\hline SHARES PERSONAL EXPERIENCE WITH AMR-TOTAL & 5.1 & 5.8 & 0.88 \\
\hline Personal experience of infections & 2.6 & 3.8 & 0.68 \\
\hline Taking personal action & 2.3 & 1.7 & 1.35 \\
\hline SHARES AMR INFORMATION AND IDEAS-TOTAL & 49.8 & 32.3 & 1.54 \\
\hline Probes the AMR issue & 46.8 & 29.4 & 1.59 \\
\hline Puts forward conspiracy theory & 2.6 & 0.3 & 8.67 \\
\hline ASSIGNS BLAME-TOTAL & 28.6 & 11.7 & 2.44 \\
\hline Industrial farming & 3.9 & 1.6 & 2.44 \\
\hline Capitalism & 3.3 & 1.1 & 3.00 \\
\hline Other countries or cultures & 3.3 & 1.4 & 2.36 \\
\hline Government & 3.0 & 0.3 & 10.00 \\
\hline Pharmaceutical industry & 2.6 & 0.5 & 5.20 \\
\hline Individual greed & 2.2 & 0.3 & 7.33 \\
\hline Lack of hygiene & 1.7 & 0.1 & 17.00 \\
\hline Abuse of antibiotics & 1.2 & 1.6 & 0.75 \\
\hline Meat eaters & 1.5 & 0.2 & 7.50 \\
\hline Ignorant people & 1.4 & 1.1 & 1.27 \\
\hline Religion & 1.3 & 0.1 & 13.00 \\
\hline PROPOSES ACTIONS-TOTAL & 21.5 & 19.1 & 1.13 \\
\hline New science & 2.3 & 6.9 & 0.33 \\
\hline Boycotting & 4.0 & 0.1 & 40.00 \\
\hline Adopt vegetarianism or veganism & 3.3 & 1.3 & 2.54 \\
\hline Political action & 3.3 & 0.6 & 5.50 \\
\hline Alternative medicine & 2.8 & 2.8 & 1.00 \\
\hline Stop overuse of antibiotics & 0.8 & 2.7 & 0.30 \\
\hline Better hygiene & 2.0 & 0.2 & 10.00 \\
\hline \multicolumn{4}{|l|}{ OTHER THEMES } \\
\hline Comment includes humour, sarcasm, satire, LOL & 2.9 & 6.6 & 0.44 \\
\hline Comment includes popular culture reference & 3.6 & 10.6 & 0.34 \\
\hline "Hateful comment" & 2.8 & 0.8 & 3.50 \\
\hline
\end{tabular}

Note: A single comment may contain multiple analytical units (engagement themes). Only engagement themes where the frequency of themes per 100 comments were greater than 1 for either "Journalism" or "Popular Science" videos were included. See Table 2 for description of Ratio. Qualifying comments $n=3,049$ ("Journalism"” =1,320, "Popular Science" =1,729). 
The journalism videos generated positive emotions where the primary feelings were expressed as empathy. After seeing personal stories of people infected by resistant bacteria or plagued by pollution from the pharmaceutical industry, YouTube viewers engaged by expressing their empathy for people involved. This was particularly prevalent in one report about the state-of-play of AMR in India. Other journalistic videos also generated expressions of empathic feelings with the animals, after exposing appalling living conditions for farm animals, such as the pigs that suffer in the food factories.

Comparing journalism with popular science, both exhibited a similar amount of emotional responses and for both video categories, negative emotions outnumber positive. For journalism, the negative emotions were mainly anger/resentment whereas comments to the popular science videos expressed worry/anxiety. When it came to audience engagement through expressions of empathy, the journalism videos clearly have the upper hand. In the popular science videos, empathy was almost absent from the comments.

\subsection{Sharing Personal Experience}

The audience also used comments to share their own experiences with AMR. In the first of two identified subthemes, viewers engaged with journalism videos by sharing their stories of getting infections or living with resistant bacteria (8).

(8) ‘ just had a staph infection but was lucky standard antibiotics killed it $i$ [sic] think $i$ [sic] feel fine no more littles sores bern [sic] 1 month i [sic] feel fine...thank god... i [sic] would of [sic] swapped with that little girl ...poor family...' (Hunting the Nightmare Bacteria)

The second sub-theme focused on what personal actions people have taken to avoid or prevent infection or mitigate the worsening of AMR, including "vegetarianism" (9), "alternative medicine" (10) and "avoiding excessive antibiotic drug use". Many of the proposed actions were, however, not at all in accordance with existing scientific knowledge or what health professionals would consider proven effective and recommend. There were various references to the use of natural remedies and herbs but also to "alternative medicine" such as colloidal silver, or even avoiding taking vaccinations.

(9) 'This is why I'm vegetarian, the meat industry is out of control.' (Pig MRSA)

(10) 'Go back to pre antibiotic treatments through herbs, foods, and silver, i [sic] use them, they work!' (Hunting the Nightmare Bacteria)

The sharing of personal experience as a form of highlevel engagement occurred at a similar rate for journalism and popular science videos. Although sharing personal experience of infection occurred at a slightly greater rate with popular science videos and sharing personal experience of taking action appeared more frequently with the journalism videos, the difference was small and suggests that journalism videos were not unique in providing a space for engaging through sharing personal experiences.

\subsection{Sharing Information and Ideas about AMR: Discussing the AMR Issue}

The analysis of YouTube comments showed that sharing information and ideas about the issue at hand was the most common expression of audience engagement identified in the corpus. It was the top theme with most engagement per 100 comments in the list of seven engagement categories (see Table 3 ).

Almost half of the analysed comments to the journalism videos involved different forms of sharing information about AMR. This high-level engagement demonstrated that viewers choose to engage by discussing, elaborating and further probing topics relating to AMR. It had several identified sub-themes: viewers posing questions in the comments, asking for clarification, and expressing their ideas and opinions on the issue (11) including sharing scientific information and experience.

(11) 'But it's the people that materialize animals and make them into a nasty shit infected hunk of meat. I think it's very unhealthy and those company's [sic] should look at the bigger picture and be smarter about their animals.' (Pig MRSA)

While the vast majority of the viewers commenting appeared to engage with AMR in an authentic and concerned manner, the factual accuracy of the comments was not always in agreement with established AMR science or expert health knowledge (12).

(12) 'The weaker the magnetic field becomes, the more likely it is to mutate virus' all over the world. the question is...what is it doing to your brain?' (Hunting the Nightmare Bacteria)

Most of the inaccuracies seem to stem from common misunderstandings and misconceptions about health and science, with quite a few also include xenophobic or racist sentiments. About three in 100 comments displayed an overt "AMR scepticism", downplaying or outright denying the problem. Almost as many put forward some version of "conspiracy theory" concerning the causes and consequences of AMR, framing the AMR as a purposefully created problem by a conspiring group of social actors including the Muslims, liberals and/or the 'globalists' (13).

(13) 'Liberals never give up lying to push their agenda. When the vegan/anti-meat crowd realized 
they couldn't get people to stop eating meat just by lying that vegan was healthier, they decided to try a different tactic: SCARE people into thinking they might get sick and DIE from it. Thus, this "pigs and MRSA" story came along.' (Pig MRSA)

Discussing the AMR topic was the most common form of engagement identified for both categories of videos. Considering that the journalism videos are current affairs investigations that attempt to explain and scrutinize antibiotic resistance as a serious and urgent social issue, this was an expected outcome. The journalism videos featured confronting materials of animals suffering in factory farming and people whose health was affected AMR, which might stir viewers to comment. However, while higher in journalism than popular science videos (49 versus 32 per 100 comments) it is contestable whether this difference is large enough to conclude that journalism videos served as a unique place for this form of engagement, encouraging public debate about the issue. One major difference uncovered in this study, that is arguably more significant, is that conspiracy theories were more than seven times more likely to be advocated in YouTube comments on journalism than popular science.

\subsection{Assigns Blame}

A significant portion of comments debating AMR also ascribed blame, responsibility and accountability for causing or exacerbating the AMR problem. In total, we identified 21 categories of blame (sub-themes) of which 11 are listed in Table 3. The five which most commonly occurred in comments to journalism videos were, starting with the most frequent, "Industrial farming" (14), "Capitalism" (15), "Other countries/cultures" (16), "Government" (17), and "Pharmaceutical industry" (18).

(14) 'Antibiotics resistance is the issue, due to farmers misusing antibiotics to fatten up their lifestock, not pork. It could happen to any type of lifestock.' (Pig MRSA)

(15) 'Truth is-it's poverty \& capitalism.' (Hunting the Nightmare Bacteria)

(16) 'Thank you india [sic], for continuing to be one of the worst shitholes on this planet. They need birth restriction so bad.' (Dark Side of India's Drug Boom)

(17) 'Sad and Tragic. It's the Indian Government's fault. Corruption is a big problem there! So, for few ppl to get rich all those poor people should suffer, right? SHAME ON YOU ALL, who are RESPONSIBLE for this situation.' (Dark Side of India's Drug Boom)

(18) 'Big Pharma is one of the most evil operations going on today.' (Dark Side of India's Drug Boom)
Some of the blaming comments were clearly derogatory of specific ethnic or religious groups. In the analysis, we attempted to identify comments that were "hateful". This is when a commenter attacks an individual or group with hateful expressions, wishing them harm or making derogatory statements. An important distinction to qualify if the comment is hateful, is when the attack was directed at an individual or group of individuals, not at an idea or ideology. All in all, approximately three of 100 comments were defined as hateful, including those that are clearly misogynist, xenophobic or even explicitly racist.

In comparison, the journalism videos exhibited blame as a form of engagement at a rate of almost 2.5 times more than popular science videos. Indeed, assigning blame was the second most common theme of engagement for the journalism videos. Given the normative role of journalism to scrutinize and investigate, this result is not surprising. Three of the top-five categories of blame were shared by both genres: "Industrial farming", "Capitalism" and "Other countries/cultures". This was somewhat surprising, since only the journalism videos focused explicitly on the negative effects of pharmaceutical industries and industrial farming and their contribution to the AMR crisis. The top categories of blame that differed between journalism and popular science videos were: "Government" and "Pharmaceutical industry" for the journalism videos; and "Abuse of antibiotics" and "Ignorant people" for the popular science videos. That lead us to conclude that journalism content appears to be associated with assigning more blame to social and economic structures, whereas comments related to popular science direct more blame to the negligence, recklessness and ignorance of individuals.

\subsection{Proposing Actions}

The final theme of audience engagement with the YouTube videos related to where viewers put forward proposed actions to combat the AMR issue. We identified 18 sub-theme categories of action of which seven are listed in Table 3, including: "political action" (15), "boycotting" (16), "adopt veganism or vegetarianism/stop eating meat" (17), "developing new science" (18), "alternative medicine" (19), "stopping the overuse of antibiotics in general" (20), and "promoting better hygiene" (21).

(15) ‘ THINK EVERYONE SHOULD WATCH THIS VIDEO THEN CALL YOUR CONGRESSMAN AND GET THEM WORKING.' (The virus that kills drug-resistant bacteria)

(16) 'And from Denmark, who is feeding their animals with GMO soya beans...don't buy Danish meat!!' (Pig MRSA)

(17) 'No, go vegan. That would eliminate the spread of super bugs altogether.' (Pig MRSA) 
(18) 'I thinks [sic] this is all good and all but Crisper 9 is a better approach to any virus or bacteria.' (The Virus that Kills Drug-Resistant Bacteria)

(19) 'It's all about drugs that don't really work, when they all just needed colloidal silver via IV.' (Hunting the Nightmare Bacteria)

(20) 'Stop using vancomycin to treat the common cold people!!! If you have absolutely 0 idea of what the hell you are doing then please don't fucking do it.... You all have caused this basically.' (Hunting the Nightmare Bacteria)

(21) 'Simple solution.... Have a good hygiene.' (Pig MRSA)

Proposing some form of action was the third most popular form of engagement and occurred equally frequently for both journalism and popular science videos. However, the repertoire of suggested actions (action categories) revealed significant differences amongst the two. For journalism videos, "boycotting" (calls for people to stop buying certain products such as Danish pork), "political action" (modifying, creating or removing policies, departments, regulations), and advocating that people refrain from eating meat (veganism or vegetarianism) were the most prevalent. In contrast, the three most frequent action proposals for popular science videos were the development of "new science" (new scientific solutions such as 'phage therapy', 'CRISPR', 'Nanobots', 'Genetic therapy', or alteration of current methods), "alternative medicine" (all alternative treatments or natural remedies, such as 'turmeric', 'cinnamon', or 'colloidal silver'), and stopping the overuse of antibiotics in general. This suggests that journalism videos were associated with political, economic and social/lifestyle actions, while popular science videos were associated with medicines, scientific or pseudo-scientific, and medical practice changes.

\section{Conclusions and Discussion}

This study explored the role journalism plays on YouTube, examining audience engagement in user comments to YouTube videos about AMR, also called "superbugs". Using a qualitative, inductive approach, we identified seven main engagement themes in the comments. Audiences expressed positive, negative or neutral sentiments about the video production, and shared their emotions, including positive emotions such as empathy and negative emotions such as anger and worry/anxiety. Commenters also shared their personal experiences with AMR by telling stories of getting infections or living with resistant bacteria. A fourth, and quantitatively dominant, engagement theme was to share information and ideas about $A M R$ such as posing questions, asking for clarification, and expressing their ideas and opinions about the issue. YouTube users also ascribed blame, responsi- bility and accountability for causing or exacerbating the AMR problem, such as blaming industrial farming or capitalism. Finally, YouTube users proposed a variety of actions to mitigate the AMR problem, such as developing new science, boycotting, or adopting a vegan or vegetarian diet. ( $A$ seventh engagement theme was coded as "other themes".)

The comparison of user comments to the journalism and popular science videos displayed different patterns of engagement. Although all seven engagement themes were present for both categories of videos, the relative emphasis varied significantly. The societal causes and the political, economic and social ramifications of AMR were much more prominent in the comments to the journalism videos. They also included more frequent calls for political action and social activism (boycotting), whereas the audience responses to the popular science videos were dominated by calls for renewed efforts to find medical and scientific solutions and general appeals to stop overusing antibiotics.

Blame assignment and accountability issues were generally more prominent in comments to the journalism videos. In particular, the comments engaged with political responsibility and accountability, something that was almost invisible in comments to the popular science videos. Hateful comments and conspiracy theories were also more frequently expressed with journalism videos, albeit less prevalent than we expected considering contemporary discussions about toxic social media environments, with frequent criticism of individual journalists and media organisations.

It is evident that the content and quality of the user comments to the videos resonates with the framing and storytelling practices of the two categories of media productions. The journalism videos are long-form current affairs productions that attempted to explain and scrutinize antibiotic resistance as a serious and urgent societal issue. Popular science videos, on the other hand, focuses on explaining the science, often using humorous cartoons in a style familiar from videogames and superhero movies to emphasise the risk associated with overusing antibiotics. This "fictionalization" of the AMR issue in popular science videos thus seems to have the (unintended and distracting) side effects of diverting the interest from the issue in focus to storytelling devises used in the video. This provides a cautionary finding for health communicators wanting to get a targeted health messaged across. The journalism videos, on the other hand, appear to stimulate political and civic engagement responses, which supports the (anticipated) democratic function of journalism in ensuring social and democratic accountability. Journalism videos also generated more empathy responses, suggesting that journalism on YouTube has a role to play telling stories about human experience that can evoke empathy amongst viewers for people affected by AMR. In the popular science videos focused on biological and scientific processes, empathy was almost absent from the comments. 
In conclusion, the study shows that there is a specific place for journalism-particularly long-form, investigative journalism - in the social media ecology. Journalism videos about AMR play an important role on YouTube by focusing on societal causes and consequences of "superbugs", thereby generating audience discussions about social and political accountability. The flipside is that this engagement also entails demonstrations of anger, hate and resentment.

The study of engagement through online comments is but one way of learning and understanding how audiences respond to journalism. Evidently, comments on YouTube are not representative of the population or even people who watches videos on YouTube. We cannot know for sure how audiences end up clicking and viewing a video on YouTube, or why some individuals decide to engage by commenting on what they see. There are possibly multiple routes to engagement. Individuals can encounter AMR content on YouTube by finding a video shared by friends, by YouTube recommendation or linked to from other websites (which seems to be quite common with the popular science videos). These multiple pathways to videos also provide an important blending of journalistic content and popular science content about important societal issues through YouTube. The present study put forward one method of revealing what engagement as 'audiences' responses to media beyond attention' may entail.

\section{Acknowledgments}

This research was supported by a Discovery Project grant from the Australian Research Council [grant number DP170100937] and by The Centre for Antibiotic Resistance Research (CARe) at University of Gothenburg, Sweden. The authors thank the issue editors Marcel Broersma and Scott Eldridge, as well as the anonymous peer reviewers, for their feedback on earlier versions of this manuscript.

\section{Conflict of interests}

The authors declare no conflict of interests.

\section{References}

Aslam, S. (2018). YouTube by the numbers: Stats, demographics \& fun facts. Omnicore. Retrieved from https://www.omnicoreagency.com/youtube-statistics

Ben-David, A., \& Soffer, O. (2018). User comments across platforms and journalistic genres. Information, Communication \& Society. doi:10.1080/1369118X.2018. 1468919

Boczkowski, P. J., \& Mitchelstein, E. (2012). How users take advantage of different forms of interactivity on online news sites: Clicking, e-mailing, and commenting. Human Communication Research, 38(1), 1-22. doi:10.1111/j.1468-2958.2011.01418.x
Braun, J., \& Gillespie, T. (2011). Hosting the public discourse, hosting the public. Journalism Practice, 5(4), 383-398. doi:10.1080/17512786.2011.557560

Briones, R., Nan, X., Madden, K., \& Waks, L. (2012). When vaccines go viral: An analysis of HPV vaccine coverage on YouTube. Health Communication, 27(5), 478-485.

Bruns, A. (2018). Gatewatching and news curation: Journalism, social media, and the public sphere. New York, NY: Peter Lang.

Burgess, J. E., \& Green, J. B. (2009). The entrepreneurial vlogger: Participatory culture beyond the professional-amateur divide. In P. Snickars \& P. Vonderau (Eds.), The YouTube reader (pp. 89-107). Stockholm: National Library of Sweden/Wallflower Press.

Burgess, J., \& Green, J. (2018). YouTube: Online video and participatory culture. Cambridge: Polity Press.

Burke Johnson, R., \& Onwuegbuzie, A. (2004). Mixed methods research: A research paradigm whose time has come. Educational Researcher, 33(7), 14-26.

Chan-Olmsted, S. M., \& Wolter, L. (2018). Perceptions and practices of media engagement: A global perspective. International Journal on Media Management, 20(1), 1-24. doi:10.1080/14241277.2017. 1402183

Cherubini, F., \& Nielsen, R. K. (2016). Editorial analytics: How news media are developing and using audience data and metrics. Oxford: Reuters Institute for the Study of Journalism.

Couldry, N. (2015). The myth of 'us': Digital networks, political change and the production of collectivity. Information, Communication \& Society, 18(6), 608-626. doi:10.1080/ 1369118X.2014.979216

Couldry, N. (2017). Reconstructing journalism's public rationale. In C. Peters \& M. Broersma (Eds.), Rethinking journalism again: Societal role and public relevance in a digital age (pp. 21-34). London: Routledge.

Couldry, N., Livingstone, S., \& Markham, T. (2010). Media consumption and public engagement: Beyond the presumption of attention. London: Palgrave Macmillan.

Hill, A., \& Steemers, J. (2017). Media industries and engagement. Media Industries, 4(1). doi:10.3998/ mij.15031809.0004.105

Kavoori, A. (2015). Making sense of YouTube. Global Media Journal: American Edition, 13(24), 1-25.

Kim, E., Hou, J., Han, J. Y., \& Himelboim, I. (2016). Predicting retweeting behavior on breast cancer social networks: Network and content characteristics. Journal of Health Communication, 21(4), 479-486. doi:10.1080/10810730.2015.1103326

Ksiazek, T. B., Peer, L., \& Lessard, K. (2016). User engagement with online news: Conceptualizing interactivity and exploring the relationship between online news videos and user comments. New Media \& Society, 18(3), 502-520. doi:10.1177/1461444814545073

Ksiazek, T. B., Peer, L., \& Zivic, A. (2015). Discussing the news: Civility and hostility in user comments. Digital Journalism, 3(6), 850-870. doi:10.1080/21670811. 2014.972079 
Lawrence, R. G., Radcliffe, D., \& Schmidt, T. R. (2018). Practicing engagement: Participatory journalism in the Web 2.0 era. Journalism Practice, 12(10), 1220-1240. doi:10.1080/17512786.2017.1391712

Lindgren, M., \& Djerf-Pierre, M. (2017). Storytelling the 'superbug crisis': Storytellers, stories, and storytelling techniques in YouTube videos about antimicrobial resistance. Paper presented at the IAMCR 2017 conference, Cartagena, Colombia.

McDermott, L. (2018). Online news comments as a public sphere forum: Deliberations on Canadian children's physical activity habits. International Review for the Sociology of Sport, 53(2), 173-196. doi:10.1177/1012690216644444

Mersey, R. D., Malthouse, E. C., \& Calder, B. J. (2010). Engagement with online media. Journal of Media Business Studies, 7(2), 39-56. doi:10.1080/16522354. 2010.11073506

Meyer, H. K., \& Carey, M. C. (2014). In moderation: Examining how journalists' attitudes toward online comments affect the creation of community. Journalism Practice, 8(2), 213-228. doi:10.1080/17512786. 2013.859838

Nelson, J. L. (2018). The elusive engagement metric. Digital Journalism, 6(4), 528-544. doi:10.1080/ 21670811.2018.1445000

Oliphant, T. (2013). User engagement with mental health videos on YouTube. Journal of the Canadian Health $\mathrm{Li}$ braries Association/Journal de L'Association des Bibliothèques de La Santé du Canada, 34(3), 153-158. doi:10.5596/c13-057

Peer, L., \& Ksiazek, T. B. (2011). YouTube and the challenge to journalism. Journalism Studies, 12(1), 45-63. doi:10.1080/1461670X.2010.511951

Peters, C., \& Broersma, M. (2017). The rhetorical illusions of news. In C. Peters \& M. Broersma (Eds.), Rethinking journalism again: Societal role and public relevance in a digital age (pp. 188-204). London: Routledge.

Powers, E. (2015). The rise of the engagement editor and what it means. Media Shift. Retrieved from http://mediashift.org/2015/08/the-rise-of-theengagement-editor-and-what-it-means

Richardson, J. E., \& Stanyer, J. (2011). Reader opinion in the digital age: Tabloid and broadsheet newspaper websites and the exercise of political voice. Journalism, 12(8), 983-1003. doi:10.1177/ 1464884911415974

Rieder, B., Matamoros-Fernandez, A., \& Coromina, O. (2018). From ranking algorithms to 'ranking cul- tures'. Investigating the modulation of visibility in YouTube search results. Convergence, 24(1), 50-68. doi:10.1177/1354856517736982

Rowe, I. (2015). Civility 2.0: A comparative analysis of incivility in online political discussion. Information, Communication \& Society, 18(2), 121-138. doi:10.1080/1369118X.2014.940365

Santana, A. D. (2015). Incivility dominates online comments on immigration. Newspaper Research Journal, 36(1), 92-107. doi:10.1177/0739532915580317

Steel, J. (2017). Reappraising journalism's normative foundations. In C. Peters \& M. Broersma (Eds.), Rethinking journalism again: Societal role and public relevance in a digital age (pp. 35-48). London: Routledge.

Stroud, N. T. J., Steiner, K., Alibhai, A., Lang, C., \& Purcell, A. (2017). Engaging news about congress: Report from a news engagement workshop. Austin, TX. Retrieved from https://mediaengagement.org/ wp-content/uploads/2017/04/Engaging-News-About -Congress-Workshop-Report.docx.pdf

Sumiala, J. M., \& Tikka, M. (2013). Broadcast yourself global-news! A netnography of the "flotilla" news on YouTube. Communication, Culture \& Critique, 6(2), 318-335. doi:10.1111/cccr.12008

Swart, J., Peters, C., \& Broersma, M. (2017). New rituals for public connection: Audiences' everyday experiences of digital journalism, civic engagement and social life. In J. Schwanholz, T. Graham, \& P. T. Stoll (Eds.), Managing democracy in the digital age: Internet regulation, social media use, and online civic engagement (pp. 181-200). Berlin: Springer

Tenenboim, O., \& Cohen, A. A. (2015). What prompts users to click and comment: A longitudinal study of online news. Journalism, 16(2), 198-217. doi:10.1177/1464884913513996

Welbourne, D., \& Grant, W. (2015). Science communication on Youtube: Factors that affect channel and video popularity. Public Understanding of Science, 25(6), 706-718. doi:10.1177/0963662515572068

World Health Organization. (2015). Global action plan on antimicrobial resistance. Geneva: World Health Organization. Retrieved from http://www.wpro. who.int/entity/drug_resistance/resources/global_ action_plan_eng.pdf

Wolfgang, J. D. (2018). How commenters use online forums as spaces for journalism's boundary work. Newspaper Research Journal, 39(1), 55-68, doi:10.1177/0739532918765468

\section{About the Authors}

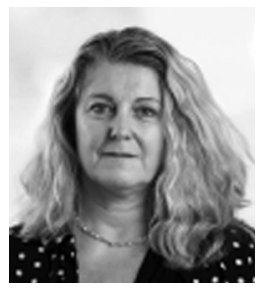

Monika Djerf-Pierre is Professor of Journalism, Media and Communication at the University of Gothenburg, and Adjunct Professor of Journalism at Monash University. Her research areas include journalism, science, risk and crisis communication, political communication, and gender studies. 


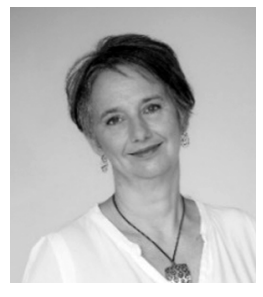

Mia Lindgren is an Associate Professor in Journalism in the School of Media, Film and Journalism at Monash University in Melbourne. Her research interests include journalism, health communication and radio/podcast studies. Mia Lindgren is Co-Editor of the Radio Journal: International Studies in Broadcast and Audio Media (Intellect, UK).

Mikayla Alexis Budinski is a Master of International Relations and a Master of Journalism graduate from Monash University, Australia. Mikayla specialises in mixed methods content analysis, which she has employed in her previous research work examining online news coverage of global terrorism, climate change and public health. She currently works as a Research Officer at the Australian Institute of Family Studies. 